\title{
El Estado reproduce la fantasía infantil: "Soñemos", de Luis César Amadori, Argentina, 1951
}

Mirta Varela ${ }^{1}$

Recibido: 21/02/2019

Aprobado por pares: 30/05/2019
Enviado a pares: $10 / 03 / 2019$

Aceptado: 04/06/2019

DOI: $10.5294 /$ pacla.2019.22.4.9

Para citar este artículo / to reference this article / para citar este artigo Varela, M. (2019). El Estado reproduce la fantasía infantil: "Soñemos", de Luis César Amadori, Argentina, 1951. Palabra Clave, 22(4), e2249. DOI: https://doi.org/10.5294/ pacla.2019.22.4.9

\section{Resumen}

Durante las primeras presidencias de Juan Domingo Perón (1946-1952) la Secretaría de Prensa y Difusión realizó filmes con el fin de exaltar proyectos impulsados por el Gobierno. Como parte de esta política de comunicación, Luis César Amadori dirigió Soñemos (1951), un mediometraje destinado a mostrar las instalaciones de la Ciudad Infantil, un hogar para niños inaugurado por la Fundación Eva Perón en 1948. Este trabajo tiene como objetivo describir y analizar las elecciones estéticas de este filme, a partir de la hipótesis de que los principales rasgos de la comunicación de Estado del periodo se encuentran condensados en esta pieza audiovisual, por efecto de la reducción de escala utilizada para la demostración de esta sociedad en miniatura. Desde el punto de vista metodológico, focalizamos en dos rasgos retóricos, entendidos como correlato formal de rasgos ideológicos: la miniaturización y la imitación. El artículo concluye que la reducción de escala permitió concretar una utopía urbana pero también mostró sus límites: uno temporal para la contención de los niños y otro espacial para la ciudad

1 orcid.org/0000-0003-0832-6526. Consejo Nacional de Investigaciones Científicas y Técnicas (Conicet), Universidad de Buenos Aires, Argentina. varelamirta@gmail.com 
cuyas fuentes productivas quedaban excluidas. La imitación, por otra parte, se enuncia como una predilección estética de los pobres que el peronismo venía a representar. Se trataba de darles el mismo lujo del que gozaban los ricos y no un nuevo estilo de vida, tal como proponían las vanguardias. Tanto la autonomía respecto de bloques geopolíticos enunciada por el peronismo como la capacidad de reproducción en el futuro de este modelo quedan irresueltos.

\section{Palabras clave (Fuente: tesauro de la Unesco)}

Historia del cine; comunicación de masas; comunicación política; propaganda; imaginación; infancia. 


\section{The State Reproduces the Children's Fantasy Soñemos by Luis César Amadori, Argentina, 1951}

\section{Abstract}

During the early administrations of Juan Domingo Perón (1946-1952), the Press and Dissemination Secretariat made films to praise projects promoted by the Government. As part of this communication policy, Luis César Amadori directed the medium-length film Soñemos (1951) that shows the facilities of Ciudad Infantil, a children's home inaugurated by the Eva Perón Foundation in 1948. This paper intends to describe and analyze the aesthetic choices of this film, based on the hypothesis that the main features of state communication in the period are condensed in this audiovisual piece, due to the scale-down used for presenting this miniature society. From the methodological point of view, we focused on two rhetorical features, understood as a formal correlative of ideological features: miniaturization and imitation. The article concludes that scale-down made it possible to materialize an urban utopia but also showed its limits: a temporary boundary for the containment of children and a spatial one for the city whose production sources were excluded. Furthermore, imitation is outlined as an aesthetic preference of the poor represented by Peronism. It was about giving them the same luxury that the rich enjoyed and not a new lifestyle, as the avant-garde proposed. Both the autonomy of geopolitical blocs proposed by Peronism and the ability to reproduce this model in the future remain unresolved.

\section{Keywords (Source: Unesco Thesaurus)}

History of cinema; mass communication; political communication; propaganda; imagination; childhood. 


\section{Estado reproduz a fantasia infantil: Soñemos, de Luis César Amadori, Argentina, 1951}

\section{Resumo}

Durante as primeiras presidências de Juan Domingo Perón (1946-1952), a Secretaria de Imprensa e Difusão realizou filmes com o objetivo de exaltar projetos impulsionados pelo governo. Como parte dessa política de comunicação, Luis César Amadori dirigiu Soñemos (1951), um média-metragem destinado a mostrar as instalações da Cidade Infantil, um abrigo para crianças inaugurado pela Fundação Eva Perón em 1948. Este trabalho tem como objetivo descrever e analisar as escolhas estéticas desse filme, a partir da hipótese de que os principais traços da comunicação de Estado do período se encontram condensados nesse projeto audiovisual, por efeito da redução de escala utilizada para demonstrar essa sociedade em miniatura. Do ponto de vista metodológico, focamos em dois traços retóricos, entendidos como correlato formal de traços ideológicos: a miniaturização e a imitação. Este artigo conclui que a redução de escala permitiu concretizar uma utopia urbana e mostrou seus limites: um temporal para a contenção das crianças e outro espacial para a cidade cujas fontes produtivas estavam excluídas. A imitação, por sua vez, é enunciada como uma predileção estética dos pobres que o peronismo vinha representar. Tratava-se de dar-lhes o mesmo luxo do qual os ricos gozavam, e não um novo estilo de vida, como propunham as vanguardas. Tanto a autonomia a respeito dos blocos geopolíticos enunciada pelo peronismo quanto a capacidade de reprodução no futuro desse modelo ficam sem resolver.

\section{Palavras-chave (Fonte: tesauro da Unesco)}

História do cinema; comunicação de massa; comunicação política; propaganda; imaginação; infancia. 


\section{Introducción}

En 1951, Luis César Amadori dirigió un cortometraje por encargo de la Secretaría de Prensa y Difusión del presidente Juan Domingo Perón que tenía como objetivo mostrar las instalaciones de la Ciudad Infantil Evita, un hogar para niños inaugurado en 1948. Sin embargo, la retórica empleada excede ampliamente las funciones informativas de un documental estatal e incita desde el título elegido — Soñemos - a estimular la fantasía del público. El modo en que los Estados modernos buscaron exaltar la imaginación ciudadana a través de la pintura, la escultura, la arquitectura, la literatura, la prensa, las celebraciones y la organización del tiempo ha sido ampliamente estudiado (Baczko, 2001), así como el modo en que esa imaginación sirvió a la construcción de la idea de nación (Anderson, 1993). En otras palabras, la pregunta que nos hacemos frente a Soñemos no es por qué un Estado buscaría incitar la imaginación ciudadana a través del cine, sino cuál fue el objetivo perseguido y a qué rasgos específicos apeló el Estado argentino entre las década de 1940 y 1950 para avivar esa imaginación. Se trata de un periodo durante el cual Juan Domingo Perón ocupó un rol protagónico: presidió la Secretaría de Trabajo a partir de 1943 y fue elegido dos veces presidente en 1946 y 1952 hasta ser derrocado por un golpe de Estado en 1955, sin que su figura pudiera ser desplazada del centro de la escena política.

Este artículo propone un análisis de Soñemos (Amadori, 1951), a partir de la hipótesis de que este filme condensa en forma ejemplar la relación entre política y cultura de masas de ese periodo y funciona, asimismo, como un repertorio para nuevas producciones posteriores. Proponemos detenernos en el análisis de dos rasgos del filme: la miniaturización y la imitación, ya que interpretamos que en ellos se condensan las principales operaciones retóricas e ideológicas del mensaje político en juego. Ambos elementos son presentados mediante diversos recursos que confluyen, sin embargo, en la construcción de un único objetivo: la presentación de una sociedad que ya ha conseguido concretar su utopía y que, por lo tanto, de allí en adelante solo necesita reproducirse a sí misma. Paradójicamente, el cambio de escala que supone la miniaturización y la sustitución de materiales implícita en la imitación abren una brecha para la corrosión y la distorsión que 
impiden justamente esa reproducción que se pretende eterna y donde, en consecuencia, la historia no parece contar con interés alguno.

El cine argentino de este periodo ha sido objeto de diversos abordajes que sirven como base para este trabajo. El rol del Estado en la producción cinematográfica durante el peronismo (Kriger, 2009) es un punto clave para ubicar este filme producido por la Secretaría de Prensa y Difusión a cargo de Raúl Apold que supo acumular poder mediante el creciente control del sistema de medios (Mercado, 2013). El análisis de los mitos producidos por el cine de este periodo (Thompson, 2014) sirve como un antecedente importante para el tipo de abordaje que proponemos en este artículo. De la misma manera, resultaron útiles los estudios previos sobre la figura del trabajador en la propaganda oficial (Gené, 2005), así como el modo en que el cine dio forma a las imágenes de género y etnicidad que el Gobierno buscaba promover (Thompson, 2014). Sin embargo, las referencias a este filme incluidas en esos trabajos no solo no agotan su sentido, sino que no se detienen en los aspectos específicos que nos proponemos indagar. Por otra parte, las historias del cine no suelen poner sus hipótesis en relación con la historia de otros medios de comunicación, lo que dificulta analizar algunos elementos en el marco de una política de comunicación como la que llevó adelante la Secretaría de Prensa y Difusión durante este periodo cuando la comunicación gubernamental fue ideada en forma unificada. De la misma manera, los trabajos dedicados a los medios de comunicación del periodo (Sirvén, 2012) abordan la prensa, la radio y la televisión, pero no suelen incluir el cine, a pesar de que su modo de producción y consumo se encuentra confundido con los demás medios. En un trabajo previo (Varela, 2007), fundamenté la necesidad de interpretar la industria cultural del periodo como una unidad y, en el mismo sentido, en las próximas páginas analizaremos el filme de Amadori (Soñemos, 1951) como una pieza de una política de comunicación unificada.

El artículo presentará, en primer lugar, los principales núcleos narrativos y personajes del filme en forma sucinta. En segundo lugar, se detendrá en el análisis de los recursos utilizados para presentar la miniaturización y la imitación. Por último, presentaremos las conclusiones de este análisis 
que atañen tanto al plano estético como ideológico de las políticas del periodo. Varios tópicos presentes en el filme - que incluyen la niñez como nostalgia y como porvenir, la relación entre la niñez y lo femenino, la modernidad neorromántica, la religiosidad y la magia, el cambio de escala y la construcción de símbolos nacionales con elementos de la cultura de masas- dialogaban con producciones internacionales de la época y fueron retomados y reformulados reiteradamente durante las décadas siguientes.

\section{Un tramo en la historia de Blanquita}

Empecemos por lo que el filme narra, exhibe y sugiere. Las primeras escenas de Soñemos (Amadori, 1951) transcurren durante una noche oscura - y amenazante - en un hogar humilde del que un hombre enfermo debe ser trasladado por una ambulancia. Su esposa es invitada por el médico a acompañarlo al hospital, pero para ello debe abandonar a su pequeña hija en soledad, no sin antes llenarla de advertencias y promesas. Sin embargo, no puede haber niños solos en el mundo feliz del peronismo y las "visitadoras" — uniformadas pero sonrientes y cariñosas — pasan a buscar a Blanquita que es interpretada por una popular actriz infantil (Diana Myriam Jones).

Blanquita, que se había quedado dormida en una fría y oscura calle de barrio, despierta alegre y segura en la luminosa Ciudad Infantil donde no se encuentran sus padres, pero donde se le permite abrazar, como compensación reparadora, una muñeca que ellos nunca pudieron comprarle. También puede gozar de la compañía de una joven preceptora vestida con traje sastre y peinada con ondas a la moda. La confusión entre ensoñación y realidad envuelve todo el recorrido por la Ciudad Infantil que, de esta manera, no puede sino representar la ciudad soñada. ${ }^{2}$

Desde el primer momento, la vida en la Ciudad Infantil se muestra simultáneamente como reglada y gozosa. Es una sociedad donde el orden, lejos de simbolizar coacción o aburrimiento, se encuentra al servicio del juego, el divertimento y el ocio. La primera regla es la separación de sexos

2 Thompson (2014) analiza el motivo del despertar de una ensoñación como un elemento central de la mitología del cine del periodo, centrándose en dos filmes de 1950: La vendedora de fantasías (Tinayre, 1950) y El crimen de Oribe (Torre, 1950). 
y la relativa homogeneidad de edades. Los varones duermen en un cuarto y las niñas en otro; mientras los varones se higienizan con agua y jabón en los baños, las niñas se peinan con moños frente al espejo. Pero todos participan por igual de esta pequeña sociedad que responde al doble mandato del deber y el placer; la moral y el deseo. Por esa razón, los niños se lavan los dientes y luego se divierten en "un mar de abundantes juguetes", en tanto que las niñas eligen sus propios vestidos de última moda pero más tarde comen "nutritivas espinacas" y todos duermen la siesta en largas filas de reposeras alrededor de una pileta de natación digna del mejor hotel de lujo que - de acuerdo con la narración en off y por si pudiera ponerse en duda que los niños estuvieran autorizados a utilizarla - "en verano florecerá de risas y de gritos". El orden no es sinónimo de rigidez o autoritarismo, porque en una sociedad donde todos son felices no es necesaria la coacción: cada uno acepta las reglas con gusto ya que han sido ideadas en beneficio e interés de todos.

Esto es aún más evidente por el hecho de que la institución no solo vino a cubrir una necesidad existente (cuidar de los niños huérfanos), sino que crea una nueva necesidad allí donde hasta el momento no existía. Aunque nadie se hubiera atrevido a reclamar al Estado el cuidado temporal de niños cuyos padres están enfermos, allí está Blanquita para demostrar que la ayuda también podía ser útil en su situación. Que la historia de Blanquita no esconda una tragedia es doblemente útil para la economía del filme, ya que si, por un lado, permite que el tono liviano y humorístico no produzca culpa o rechazo en el espectador, por otro, también permite mostrar la ilimitada acción solidaria de la Fundación de Ayuda Social que el público reconocerá fácilmente como Fundación Evita. ${ }^{4}$

La única nube dentro de la calma y armonía de la Ciudad Infantil proviene de la falta de noticias sobre la salud del padre de Blanquita. Pero inmediatamente la preceptora viene en su auxilio para que la niña pueda llamar por teléfono y enterarse de que se encuentra mucho mejor. Como la salud

3 Utilizo las comillas para las citas textuales de la voz en off del filme.

4 Conocida popularmente como Fundación Evita, en verdad se denominaba oficialmente Fundación de Ayuda Social María Eva Duarte de Perón desde su creación en 1948 y cambió su nombre por Fundación Eva Perón en 1950. 
no solo depende de la labor de los médicos, Blanquita va a la Iglesia a agradecer a Dios por salvar a su padre. De esta forma, salvo los imponderables que no dependen de los hombres (como señala la voz en off: "El destino [... ] no siempre es bueno con los buenos"), todas las soluciones a los problemas de la vida social están contenidas en las delegaciones de la Policía, el Gobierno municipal y el activo comercio de la Ciudad Infantil, lo cual sugiere que esta sociedad es más justa que la creada por Dios, pero, por las dudas, las niñas no dejan de rezar en la Iglesia con sus mantillas blancas que las hacen parecer como pequeñas novias.

Los niños circulan en autos que van al taller mecánico y las niñas van a hacer compras al Mercado 17 de Octubre. Pero como Blanquita es una "flamante ciudadana" - y no una rica heredera - no puede hacer sus compras en el mercado porque no tiene dinero. Sin embargo, "para eso se han hecho las instituciones de crédito”, acota la narradora. Entonces va al banco a pedir un préstamo para comprar fruta, y como la niña es muy responsable, pregunta cuándo deberá devolverlo. La respuesta del cajero no se hace esperar: "El día que los pajaritos hablen y las vacas vuelen".

Luego va de visita a la casa de Rodolfito que se ha comportado como un verdadero galán desde su llegada. Mientras la pequeña pareja permanece sentada en Villa Evita, una niña limpia afanosamente y otra les sirve el té. Mientras Rodolfito viste chaleco y camisa para recibir a Blanquita que ya se ha cambiado el vestido matinal por otro igualmente primoroso, las niñas que forman parte del servicio doméstico llevan un pañuelo atado a la cabeza. En la Ciudad Infantil, las diferencias de clase no desaparecieron, pero se puede ver un desplazamiento que las hace coincidir con las fronteras entre lo rural y lo urbano. Así, dos niñas vestidas de paisanas barren la vereda del mercado y los únicos presos dentro de la cárcel están vestidos de gauchos, lo que demuestra que el mundo rural no es en absoluto deseable.

La Ciudad Infantil no necesita explicar que el modelo social que propone es eminentemente urbano, eso es lo que muestra y exhibe. El mundo feliz es ciudadano. Por eso, las diferencias raciales y de edad — que es evidente que no pueden ser suprimidas - son marcadas para anunciar que to- 
dos gozan de iguales beneficios porque han sido suprimidas las injusticias. El filme se detiene, por ejemplo, en la imagen de una niña rubia y una "morochita"; una niña negra (cuya imagen ilustra la idea enunciada por la locutora de que "el apetito no entiende de colores") y Blanquita, cuyo nombre no deja espacio para las sutilezas. Ambas gozan de los cuidados y de las instalaciones de la Ciudad Infantil.

La vida pública también incluye la asistencia al teatro y a un acto político. "El señor intendente, elegido por sufragio popular, está repartiendo caramelos al pueblo", señala la voz en off, mientras se muestra al funcionario saludando desde el balcón de la Municipalidad. Y agrega: "La Policía también es el pueblo”, mientras entrega caramelos a los policías que lo rodean.

Al caer la noche, Blanquita sigue pensando que todo eso es demasiado bello para ser verdad. Sin embargo, la clave se encuentra en un mural donde la bella durmiente está acompañada por "una aparición hermosa y dulce, con una estrella en la frente y la varita mágica de los milagros".

- La que me trajo aquí es el hada buena de las niñas, ¿no es cierto?

- Sí, fue el hada o algo parecido.

— ¿Esa señora es el hada? [pregunta Blanquita mientras la cámara muestra un retrato dibujado de Evita sonriente]

- No, Blanquita, es solamente una mujer, un corazón, una compañera de todos los humildes y la esperanza de todos los indefensos.

En fin, el hada ha encarnado en Eva Perón.

Es significativo que el relato no cierra la historia individual, no nos muestra el reencuentro de Blanquita con su padre recuperado o la vuelta al hogar. Por el contrario, el filme concluye con escenas de multitudes infantiles gozosas y un plano aéreo que se aleja de la Ciudad Infantil hasta mostrarla a otra escala, como si fuera un esquema de pequeñas calles y edificios. La voz en off señala:

Así comienza un nuevo y límpido sueño de niño. Bajo el techo de la Ciudad Infantil, la urbe maravillosa poblada de pequeños habitantes que sueñan noche y día con los ojos cerrados y con los ojos abiertos. 
En esta Ciudad Infantil, que evoca un cuento de hadas y que es, sin embargo, una tierna realidad gracias a Eva Perón, la extraordinaria mujer que no duerme para que los niños de la patria sueñen y para cumplir el más íntimo anhelo del general Perón: que los argentinos sean un poco más felices viendo soñar a sus hijos.

\section{La miniatura: Io infantil y lo femenino}

En la Ciudad Infantil, todo es perfecto a condición de que sea pequeño: un mundo feliz condenado a no crecer. De ahí que la frontera entre el sueño y la realidad se presente, simultáneamente, como un límite de escala. El proyecto de la Fundación Evita tenía como objetivo la atención de 450 niños que no podían superar los 7 años. Si bien las políticas sociales del Gobierno preveían otros hogares para niños mayores, jóvenes y adultos (la Ciudad Estudiantil ocupaba un predio cercano a la Ciudad Infantil y también dio lugar a otro cortometraje llamado Ahora soy un más [Soria, 1952]), el sueño hecho realidad de la Ciudad Infantil ya no podría repetirse en esa forma de comunidad soñada y fantasiosa.

El proyecto de la Fundación Evita tenía entre sus principales objetivos el contacto fluido con otros niños que no vivían allí. A diferencia de los hogares para huérfanos que existían hasta entonces, en la Ciudad Infantil convivían residentes permanentes con niños que solo habitaban la ciudad durante el día. Todos debían asistir por igual a escuelas públicas comunes. De esta forma, se garantizaba que las instalaciones fueran conocidas y aprovechadas por un número mayor de niños y adultos.

Sin embargo, contra esta premisa, Soñemos de Amadori (1951) muestra una comunidad cerrada de la que no se sale por la puerta sino por arriba. Literalmente, durante la escena final, la mirada del espectador se aleja de la ciudad y la sobrevuela. El plano aéreo muestra la ciudad como un conjunto artificial, como si se tratara de una maqueta cada vez más pequeña, a medida que la cámara se aleja. Y sin contacto con la ciudad real porque no se muestran las calles o el barrio de Belgrano donde estaba emplazada. En este sentido, la pequeñez se muestra como protección pero se vislumbra su contracara: el artificio y el encierro. 
Durante su inauguración, Eva Duarte repitió una frase que ya había pronunciado en otras ocasiones: "un país que olvida a los niños, renuncia a su porvenir". Efectivamente, los niños aspiran al crecimiento y una ciudad que no puede contener a los adultos en que devendrán resulta un límite para su futuro. ¿Pero cuál es el futuro que se ofrece a los niños en Soñemos?

Los únicos adultos visibles en la Ciudad Infantil son mujeres. ¿Se trata de una prueba de su propia pequeñez y fragilidad? ¿O demuestran que serían las más aptas para la supervivencia en el porvenir justicialista? Es notable que tanto la ambulancia en la que trasladan al padre enfermo como la camioneta donde llevan a Blanquita hasta la Ciudad Infantil sean conducidas por mujeres. La presencia de mujeres en roles habitualmente desempeñados por hombres - choferes - no se reproduce en las escenas de la vida infantil en la ciudad donde las niñas barren y los varones conducen los autos. Sin embargo, el protagonismo femenino en la ciudad soñada es indiscutible y no puede ser contrarrestado por un padre enfermo y ausente. El "avance" de la mujer sobre roles hasta entonces vedados fue motivo de otro cortometraje argumental de la Secretaría de Prensa y Difusión, La mujer puede y debe votar (Barth, 1951), donde se difunden las ventajas del voto femenino. Sin embargo, la modernidad de esas imágenes femeninas cívicas es contrarrestada permanentemente por las aspiraciones femeninas impuestas por la cultura de masas, donde las mujeres se presentan como un blanco más fácil de la sociedad de consumo. Así es como, mientras los niños parecen uniformados y relativamente ascéticos, las niñas eligen vestidos llenos de tablas, frunces y volados, de diferentes texturas y cortes, aunque todos a la moda. Sin embargo, si las niñas y mujeres son protagonistas de la vida en la ciudad, son los varones quienes ocupan los puestos de poder: intendente, comisario, policías y banqueros. La ambulancia puede ser manejada por una mujer pero el médico es un hombre, y la enfermera, una enfermera. El orden femenino de la Ciudad Infantil descansa sobre el goce de un tiempo y un espacio de juego, aprendizaje, diversión y cuidados cuya protección descansa en la ley y el gobierno masculinos representados en última instancia por el retrato del presidente Perón, estratégicamente ubicado detrás del escritorio del comisario. 
La voz de Fanny Navarro conduce la narración del filme. Fanny Navarro, antes de convertirse en la esposa de Juan Duarte - hermano de Eva Duarte - y en la presidenta del Ateneo Cultural Eva Perón, había encarnado roles de femme fatale en numerosos filmes y condensa ejemplarmente la tensión entre el protagonismo femenino y la mirada masculina que construye su atractivo. Aunque parezca a priori difícil de justificar, en Soñemos (Amadori, 1951) el juego infantil, el cuidado maternal y la sensualidad femenina no resultan incompatibles. Esto es así porque la mujer puede ocupar roles de gran esmero, pero elige ponerse al servicio de la estrategia y la fuerza masculinas, así como al cuidado de su galantería. De la misma manera, durante la inauguración de la Ciudad Infantil, Eva Duarte se presenta como "humilde pero apasionada colaboradora del general Perón que ha querido honrar con su presencia este acto de la Fundación de Ayuda Social".

La escala reducida de la ciudad se completa en el filme con el empleo reiterado de diminutivos en el lenguaje oral: los protagonistas se llaman Blanquita y Rodolfito, los padres son nombrados como papito, mamita o madrecita, la abuela como abuelita y todos se dan besitos. Aunque no es el único efecto perseguido, resulta inevitable la asociación con el nombre popularizado en diminutivo que impregnaba la política de esos años: Evita. Pero la sucesión de pequeñas palabras, pequeñas personitas y pequeños objetos produce, paradójicamente, un efecto de exageración y exceso permanentes. Las paredes blancas están pintadas con murales detallistas, los espacios amplios se encuentran llenos de pequeños muebles decorativos; de los techos del comedor cuelgan vigas festoneadas, y de los grandes ventanales, cortinas con volados. Durante el almuerzo, la cámara se detiene en las decoraciones de los muros que la narración define como "del más rancio clasicismo liliputiense: Blancanieves rodeada de enanitos, las chozas de Honguilandia, el príncipe encantado, el dragón de las siete cabezas; no podía faltar Caperucita Roja y el lobo que se disfrazó de abuelita". El "clasicismo liliputiense" encierra una tensión entre lo sublime y lo pintoresco, el monumento y la miniatura, lo moderno y lo neorromántico, que se manifiesta a cada paso de la Ciudad Infantil. 


\section{Lo simultáneamente nuevo o la utopía realizada}

Lo nuevo pero acabado es otra de las expresiones de este estilo. Los edificios y los objetos deben parecer nuevos pero les está vedado producir la impresión de que aún les resta algún vacío a ser llenado. A diferencia de los barrios de vivienda social recién terminados, donde los edificios suelen mostrarse total o parcialmente vacíos y las calles con árboles recién plantados que aún no proyectan sombra, la Ciudad Infantil se muestra completamente habitada. Pero con una vida artificial. Está habitada como puede estarlo el hogar de una publicidad comercial donde todo es simultáneamente nuevo. Sin embargo, la novedad absoluta - y homogénea- es incompatible con el uso cotidiano de los objetos y el modo en que transcurre habitualmente la vida. Contrasta con el modo en que pueden vivir ociosamente los viejos burgueses que habitan mansiones pobladas de recuerdos y de objetos cargados de historia, pero también con cualquier hogar pobre o de clase media - que compra a crédito - donde resulta imposible que todos los objetos sean simultáneamente nuevos. ${ }^{5}$

Aquí, por el contrario, los objetos son nuevos porque la ciudad ha sido ideada para "flamantes ciudadanos", como define la narradora a Blanquita. La fórmula es clave para comprender las relaciones entre política, mercado y sociedad en la Ciudad Infantil. Aquellos que cuentan con el dinero de su herencia siempre han sido considerados ciudadanos. Por el contrario, los pobres nunca han gozado de los mismos derechos. En este esquema, el consumo, la ostentación y el lujo no solo caracterizan al nuevo rico, sino que le otorgan carta de ciudadanía a los pobres y desamparados. Por eso, el dinero no solo debe servir para cubrir necesidades básicas sino para el lujo, que no puede ser explicado únicamente como revanchismo social, la reacción instintiva a la miseria. En La razón de mi vida, Eva Duarte señala, a propósito de los hogares para niños construidos por su fundación:

Mis "hogares" son generosamente ricos... más aún, quiero excederme en esto. Quiero que sean lujosos. Precisamente porque un siglo de asilos miserables no se puede borrar sino con otro siglo de hogares "excesivamente lujosos". Sí. Excesivamente lujosos. [...] No, no

5 Otro de los cortometrajes realizados por la Secretaría de Prensa y Difusión lleva por título Payadas del tiempo nuevo (Pappier, 1950) donde lo nuevo, en cambio, se presenta en tensión con lo tradicional (las payadas). 
tengo miedo (de que los pobres se acostumbren a vivir como ricos). Por el contrario; yo deseo que se acostumbren a vivir como ricos... que se sientan dignos de vivir en la mayor riqueza... al fin de cuentas todos tienen derecho a ser ricos en esta tierra argentina. (citado por Ballent, 2005, p. 167)

De esta manera, en el filme el lujo es un derecho porque en Argentina se gobierna según la expresión de una concepción republicana sui generis en que el pobre - por ser pobre - cuenta con una ciudadanía degradada en relación con el rico. El lujo es alcanzado en un tiempo soñado de ampliación de derechos, de ahí que en la Ciudad Infantil los espacios públicos bautizados con alguna referencia histórica son el Mercado 17 de Octubre y la Plaza de los Derechos del Trabajador. ${ }^{6}$ No solo no se cuestiona la asociación entre riqueza y ciudadanía, sino que, muy por el contrario, se la reafirma por diferentes caminos. Por ejemplo, la sobreimpresión —o confusión, según como se la interprete- entre propaganda política y publicidad comercial. Como una de las acusaciones más despectivas que podían imputársele a la cultura de este periodo, Jorge Luis Borges escribió en 1955 para la revista Sur que los métodos de la propaganda comercial "fueron aplicados al gobierno de la República [... con la tenacidad que usan las empresas para imponer navajas, cigarrillos o máquinas de lavar" (p. 9).

Soñemos no solo muestra el modo en que se ha superado el ascetismo y la uniformidad de los antiguos hogares y asilos, sino que podría confundirse fácilmente con la promoción de un parque temático o el catálogo de una juguetería de lujo. Cuando la voz de Fanny Navarro dice que "la colmena sigue llenándose pero no importa [porque] hay juguetes para todos y para todas", resume el modo en que el consumo se ha vuelto necesario, universal y al mismo tiempo individualizado. Mientras en los viejos hogares para niños huérfanos los uniformes, los cortes de pelo higiénicos y los espacios despojados eran la norma, en la Ciudad Infantil cada niña puede elegir su propio vestido y hay un juguete para todos y todas. La sociedad de masas

6 El 17 de octubre de 1945 tuvo lugar una masiva movilización en reclamo de la liberación de Juan Domingo Perón que, luego de una visible gestión a cargo de la Secretaría de Trabajo, había sido encarcelado. El peronismo instauró ese acontecimiento como su hito fundacional, y desde el momento en que Perón gana las elecciones en 1946, se convierte en el Día de la Lealtad Peronista que adquiere estatuto de celebración oficial. Tanto el 17 de octubre como el 1 de mayo darían ocasión a multitudinarias concentraciones durante este periodo. 
que instaura el peronismo viene a dejar atrás otra sociedad que también era de masas pero donde su carácter homogeneizante no se complementaba adecuadamente con el carácter individualizante de la sociedad de consumo. Los uniformes utilizados en el filme permiten ver este doble carácter de la sociedad de masas peronista. Las "visitadoras" que llevan a Blanquita a la Ciudad Infantil están vestidas con uniformes que podrían parecer de la Policía o del Ejército. Sin embargo, sus peinados y sus sonrisas contradicen las reminiscencias represivas de esos uniformes. En la Ciudad Infantil, se puede vestir uniforme pero procurar un cuidado femenino que se pretende siempre individualizado y maternal. Las escuelas públicas que promovieron la uniformidad del delantal blanco obligatorio en Argentina o la arquitectura higiénica de hogares y hospitales incluían al pobre en los derechos a la educación y a la salud, pero lo excluían de la ensoñación y el deseo. El filme comunica que el Gobierno de Perón no trataría de incluir a los trabajadores como ciudadanos de la República, sino de darles a los "flamantes ciudadanos" crédito ilimitado para hacer sus compras en el Mercado 17 de Octubre que no solo ofrece carne y verdura, sino también vestidos, zapatos y adornos. El crédito es ilimitado porque es visto desde el punto de vista del ciudadano para quien es una necesidad y no desde el punto de vista del banco para quien es una renta. El filme traduce el dinero al frío lenguaje de la economía (instituciones de crédito), pero luego lo vuelve a traducir al lenguaje popular (será devuelto "el día que las vacas vuelen").

Sin embargo, la anticipación del cumplimiento del deseo que permite el crédito no se efectiviza sin problemas. Los objetos deseados necesitan un cierto tiempo acumulado (de producción o de herencia, según el caso) con el que no cuenta esta sociedad de flamantes ciudadanos sobre los que pesa un límite temporal perentorio, condenados como están a no crecer más allá de los 7 años. Aun así, Eva Duarte destaca en su discurso inaugural la celeridad con que se han realizado las obras, en sus propias palabras, que "el prodigio de que esta magnífica realidad que vemos, haya sido realizada en el milagroso e increíble lapso de cinco meses y veinte días". A continuación, aclara que también es milagroso que en su costo "se haya invertido tan solo un millón doscientos mil pesos, cifra mínima si se considera la importancia, magnificencia y proyecciones de la obra que contemplamos". Sin embargo, esto no ha sido un milagro, sino que ha sido posible gracias a "las firmas que con sus 
donaciones han colaborado con la Fundación que presido para equipar y dar el confort a esta Ciudad Infantil de ensueño". De esta manera, los esfuerzos del Gobierno del general Perón, la fundación que su esposa preside y los empresarios se muestran complementarios y poderosos. La mediación de la Fundación Evita resulta un eslabón clave de esa concepción republicana sui generis donde no es el Gobierno el que recibe dinero de los empresarios (al menos en este caso en particular), sino que es una fundación que tiene por objetivo cumplir los deseos del presidente de la república.

\section{La imitación y el deseo}

El rumor de que Walt Disney conoció la Ciudad Infantil y la tomó como modelo para Disneyland que fue inaugurado en 1955 podría contar con "pruebas irrefutables" en muchas escenas del filme de Amadori (Soñemos, 1951): la escala de la ciudad, sus torrecitas, los personajes de cuentos infantiles, la vajilla decorada con patos de anchas caderas... Para refutar el rumor, no alcanza con señalar que la Ciudad Infantil respondía a un proyecto educativo, en tanto que Walt Disney construyó un parque de diversiones. Por el contrario, se impone la pregunta acerca de si era deseable imitarlo. Resulta dudoso que el mérito de inspirar a Disney — que sin duda hubiera despertado la ensoñación de la Secretaría de Prensa y Difusión — resultara un plus para una ciudad infantil que parecía aspirar, por el contrario, a mostrarse como copia de un original deseable. Desde su concepción, la ciudad es un modelo derivado, una ciudad adulta a escala reducida. Pero, paradójicamente, el original adulto no respondía a ninguna ciudad histórica. La Ciudad Infantil no era como los parques que representan a Europa con pequeños monumentos de cada una de sus capitales o como Legoland donde los edificios estaban construidos en miniatura con materiales artificiales. Mucho menos podría buscarse su original en la ciudad de Buenos Aires: las calles curvas, los arroyos serpenteantes, los puentecitos arqueados y las lagunas artificiales se encuentran en las antípodas de la cuadrícula porteña donde la Ciudad Infantil fue emplazada. Solo Ciudad Evita, una ciudad completamente nueva inaugurada en 1948, podía funcionar como modelo. De hecho, en el filme de Amadori (Soñemos, 1951), la vista aérea final de la Ciudad Infantil funcionaba tal vez como guiño a un espectador que conocía el secreto a voces de que desde los vuelos que partían del tam- 
bién recientemente inaugurado Aeropuerto de Ezeiza en 1949 podía reconocerse el perfil de Eva Duarte en el plano irregular de Ciudad Evita.

Los elementos neorrománticos de la arquitectura de la ciudad, como puentecitos, arcos o torrecitas con reminiscencias góticas, no solo le otorgan pintoresquismo al conjunto, sino que también le suman un rasgo nostálgico y, por lo tanto, una dosis de tiempo acumulado en forma artificial. En el mismo sentido, Ballent (2005) observó que las obras del peronismo

\begin{abstract}
no pretendían deslumbrar por su carácter innovador ni por su acierto técnico, sino apelar a imágenes asociadas con el habitar de los sectores altos y medios, muy difundidas por la prensa y el cine, pero alejadas de las formas concretas del habitar popular masivo. Acercaban al mundo popular lo que se había construido en décadas anteriores como imagen de casa "cómoda", "coqueta", "alegre" y "humana". (pp. 101)
\end{abstract}

La imitación y el reemplazo de materiales originales por sucedáneos que caracterizan al kitsch (Moles, 1990) adquieren una gran complejidad en la cultura de masas del primer peronismo. De ahí que la idea de que la Ciudad Infantil sea el original del parque de diversiones construido por Disney (y no a la inversa), lejos de resultar halagador, resulta perturbador para el proyecto. El peronismo buscaba repartir entre los niños desvalidos el mismo lujo (y no otro distinto) con el que contaban los niños ricos. Pero la celeridad del proyecto complicaba las opciones estéticas que debían conservar rasgos del deseo infantil de quienes eran entonces adultos (y debía ser por lo tanto levemente nostálgico), pero activar elementos de lo permanentemente nuevo (y por lo tanto efímero) de la cultura de masas. La extrema modernidad del proyecto y el tiempo acumulado indispensable para conseguir un lujo como el de los ricos pone en tensión permanente este modelo de sociedad.

El ballet clásico representado por los niños en el teatro de la Ciudad Infantil contiene esa mezcla de pretensión cultural por lo que se reconoce como alta cultura universal, el cambio de escala y el exceso propio del kitsch, así como la tensión entre lo nuevo y lo imitado. La sala llena de murales parece aludir a la sala de los cantores del castillo de Neuschwanstein que sirvió 
como modelo para el castillo de Disney. Neuschwanstein — como todos los castillos que mandó a construir Ludwig II de Baviera en la segunda mitad del siglo XIX - es un castillo fuera de época, construido cuando los castillos ya no cumplían las funciones de los modelos que imitaban. Se trata de una construcción neorromántica y neogótica, que incluyó, sin embargo, los últimos adelantos de la tecnología de su época (cableado eléctrico y teléfono, por ejemplo), revestida de piedras que imitaban grutas, cuartos con mobiliarios góticos y una sala dedicada a Richard Wagner. No por casualidad se trata del mayor atractivo turístico de Alemania que, sin embargo, no consigue el grado de popularidad del castillo de Disney que se propuso imitarlo más de medio siglo más tarde (como una prueba de que la popularidad aumenta en las versiones derivadas antes que en los originales). Neuschwanstein condensa las tensiones entre imitación y novedad, abigarramiento y practicidad, asincronía y tecnología, pintoresquismo y monumentalismo. El castillo se encuentra emplazado en los Alpes, rodeado de precipicios y bosques, y con vistas a un lago que le da el marco adecuado para la ensoñación. La historia de su construcción también expresa lo efímero de lo que ha sido proyectado como perenne: Ludwig II pasó a la historia como un excéntrico constructor de castillos kitsch y como último príncipe de Baviera que nunca llegaría a habitar Neuschwanstein.

Lo que se entiende por "cultura" en la Ciudad Infantil exuda pretensión y academicismo. El ballet ocupa un lugar central en el teatro de la ciudad: se compara a una niña con una figura de Degas y a otra con una pequeña Pavlova. En la sala de dibujo, "los infantes se divierten mientras aprenden el arte de Rafael y Velázquez”. Los niños que pintan, bailan o ejecutan instrumentos parecen disfrutar con ello. Pero el teatro es también un espacio competitivo donde las jerarquías pueden mantenerse, por eso se destaca el rol del director de orquesta y el camerino de la "primera actriz" que interpreta a Caperucita Roja. La voz de Fanny Navarro observa que el público que asiste a "este templo del arte" cuenta "con la más completa guardarropía de oropeles, sedas y lentejuelas”, y es muy exigente. La cultura no se experimenta, se juzga. Y se le exige calidad como a cualquier otro producto de consumo. O más que a cualquier otro porque es uno de los que distingue con mayor claridad las jerarquías sociales en juego. 


\section{Conclusiones}

Soñemos (Amadori, 1951) nos cuenta un tramo excepcional de la historia de su protagonista. Apenas unos días en la vida de una niña de pocos recursos cuyo padre enferma y debe ser hospitalizado. El Estado se ocupa de la enfermedad del padre y del cuidado de la hija: lo hace con eficiencia y buscando cumplir, además, los sueños infantiles que se proponen al espectador como la aspiración más genuina de una sociedad. De ahí que la historia de esta niña es apenas una excusa para mostrar la ejemplar Ciudad Infantil creada por la Fundación Eva Perón, y mientras la historia individual queda abierta, el filme concluye con la imagen de la ciudad y de muchos otros niños en condiciones similares.

El diminutivo elegido para nombrar a la protagonista (Blanquita) remite al de Eva Duarte, también conocida popularmente por su diminutivo (Evita), y subraya dos aspectos que son condición indispensable para el funcionamiento de la ciudad soñada: la pequeñez y la imitación de un modelo. Ambos aspectos se refuerzan y multiplican en el filme: el detallismo, los decorados abigarrados, el vestuario lleno de pliegues y los diminutivos van de la mano de la imitación de modelos exaltados por la cultura de masas.

Preferir la imitación y descartar una originalidad radical son elecciones que sirven para enunciar un postulado básico del filme. Soñemos (Amadori, 1951) enuncia que los pobres y desheredados tienen derecho ( $y$ además prefieren) el mismo lujo del que gozan los ricos (al menos el lujo del que gozan los ricos en las películas) y no otra nueva forma de vida que desecha el lujo (tal como proponían las vanguardias y las utopías políticas de izquierda). La oposición entre cultura de masas y vanguardia se encuentra en la base de las elecciones estéticas del peronismo que el filme viene a comunicar. El Gobierno peronista no pretende crear ex nihilo, sino a partir del deseo de los pobres. Pero como es sabido la disputa por la interpretación de ese deseo atraviesa la política por completo.

Otro eje de disputa es, sin duda, el de la historia. En la Ciudad Infantil, las referencias históricas son muy limitadas: apenas dos fechas (el 4 de 
junio y el 17 de octubre), dos retratos (de Juan Domingo y Eva Perón) y una bandera flameando que permite constatar que aún nos encontramos en Argentina. Pero una Argentina completamente nueva cuya historia comienza el 4 de junio de 1943, fecha del golpe de Estado del que Perón participó y que puso fin a un periodo que ha pasado a la historia argentina como la década infame. Perón no solo propone dejar atrás esa década e iniciar una nueva etapa, sino fundar una nueva Argentina, transformar las ideas que la sustentaban como nación.

¿Con qué elementos propuso hacerlo? Excepto por un plano rápido de la bandera argentina, la Ciudad Infantil podría estar emplazada en cualquier lugar del mundo donde el ballet clásico, los pintores renacentistas y los cuentos románticos forman parte de una cultura universal común. De esta manera, la cultura soñada está lejos de contener elementos nacionalistas. Tampoco incluye referencias a la industria cultural, que provoca la ensoñación infantil pero jamás se hace explícita en el filme. Soñemos (Amadori, 1951) no cita a Disney o a Hollywood, sino que propone elaborar algo original con los mismos materiales con los que Disney amasó Blancanieves, Fantasía y el castillo de su tierra de ensueño.

Las confluencias entre Disney y la Ciudad Infantil retratada en el filme no son azarosas. Amadori (1951), además de ser elegido por la Secretaría de Prensa y Difusión para rodar este cortometraje, también fue elegido por Walt Disney para dirigir el doblaje al español de Fantasía, Pinocho, Dumbo y Bambi. En varias de sus películas —la mítica Madreselva [1938)] entre ellas - había contado, asimismo, con la fotografía de John Alton, antes de que este desarrollara su carrera en Hollywood.

La originalidad de la cultura de este periodo no consiste simplemente en la adaptación de una cultura universal o de una cultura de masas promovida por otras naciones. La referencia al castillo de Neuschwanstein permite valorar la verdadera escala del sueño de la Ciudad Infantil que exige pequeñez en lo individual, pero no deja de tener grandes pretensiones en lo político. Aunque para el peronismo no era importante la originalidad estética, no elige imitar un modelo exclusivo, sino mezclar elementos de diver- 
sos orígenes. ${ }^{7}$ Por eso, puede adelantarse en la utilización del modelo que va a servir a Walt Disney y hacer con eso algo distinto. Esta decisión suponía ubicarse en una posición competitiva y, por eso mismo, amenazante en el contexto internacional.

Si bien el campo - tanto desde el punto de vista productivo como paisajístico - se encuentra ausente de la Ciudad Infantil, la utopía urbana encarnada en "esta villa magníficamente organizada" es la de una ciudad improductiva donde no existen obreros ni fábricas, sino empleados de servicios, funcionarios y pequeños comerciantes. De esta forma, no solo se elide el campo sino la producción misma. Y tal como señalamos, también la historia. La ciudad soñada por el peronismo se asemeja, en este punto, a los proyectos suburbanos de posguerra que sirven como ciudades dormitorio y unidades de consumo que proponían implantarse sobre un vacío. Vale la pena considerar que el filme fue estrenado el mismo año en que el Gobierno de Perón inaugura las transmisiones televisivas en la ciudad de Buenos Aires. Y como señala Williams (1992), la televisión fue un vehículo de promoción del suburbio dominado por la vivienda unifamiliar, el pequeño jardincito y el automóvil. Es decir, el modelo exhibido en la Ciudad Infantil y en Ciudad Evita. Paradójicamente, la modernidad exhibida por el filme en algunas áreas de la ciudad contrasta con la antigüedad de los medios de comunicación empleados. ${ }^{8}$ En Soñemos (Amadori, 1951), la comunicación con el mundo se realiza a través del correo y el teléfono. La política se desarrolla en la plaza, con la presencia del intendente en el balcón de la $\mathrm{Mu}$ nicipalidad y la cultura en el teatro. $\mathrm{Ni}$ el cine, ni la radio, ni la televisión están presentes.

En este sentido, Soñemos (Amadori, 1951) expone una serie de problemas que han atravesado desde entonces la relación entre política y cultura en Argentina. El peronismo se adjudicó la capacidad de hacer confluir

7 Gené (2005) discute la asociación fácil entre peronismo, nazismo y fascismo. Por el contrario, encuentra rasgos que participan de una misma época cuando coexisten la estética soviética, la estética de la Alemania nazi y la estética norteamericana del New Deal.

8 Es exactamente lo opuesto de lo que se había realizado en el castillo de Neuschwanstein donde una arquitectura que retomaba elementos del pasado no dudaba en incorporar los medios de comunicación más modernos. 
las banderas nacionales con los intereses de las clases populares, a partir del presupuesto de que las élites argentinas habían oscilado entre el nacionalismo oligárquico y un liberalismo que respondía a intereses ajenos al país. Por eso, descarta los símbolos del nacionalismo, siempre ligados a las tradiciones rurales (el gaucho y el caballo, por ejemplo) y también los de una cultura urbana anclada en la ciudad de Buenos Aires (que incluía a artistas e intelectuales pendientes de una cultura "universal" de élite que no podía representar ni a las masas ni a la nación).

De esta manera, la cultura propuesta por el peronismo no solo presupone que la cultura de élite (nacionalista o liberal) no puede representar una auténtica cultura nacional. También presupone que la cultura de masas (y no la cultura popular tradicional reivindicada por los sectores nacionalistas) representa los gustos e intereses de los sectores populares y es, además, la cultura moderna que conviene a estos sectores (por contraposición a la modernidad de las vanguardias, contemporáneas al ascenso del radicalismo en Argentina). No se trata únicamente del enfrentamiento entre una cultura universal y una cultura nacional-popular, sino del rol que una industria cultural moderna y nacional podía adoptar en esta nueva sociedad.

El carácter derivado y de imitación de las producciones realizadas por el Estado durante esta etapa podría inducirnos a pensar en una imitación o adaptación de la cultura de masas hegemónicamente norteamericana. En este sentido es que he interpretado en otro momento (Varela, 2006) la estética del primer peronismo como una forma de "criollización". El término criollo designaba a los nacidos en suelo americano de padre o madre españoles, pero durante el periodo inmigratorio de fines del siglo XIX y principios del siglo XX pasó a ser reivindicado por aquellos que aun contando con sangre europea ya contaban con mucho tiempo en esta tierra. En una cultura afincada en un territorio extenso, donde la lengua, la raza y la religión son comunes a muchas otras naciones, el tiempo de permanencia en la tierra fue un blasón que permitió distinguir entre "criollos viejos" " "recién llegados". Soñemos (Amadori, 1951) pretende incluir a nativos e inmigrantes, pero apela particularmente a los "recién llegados" a la sociedad de consumo. 
La concepción de lo nuevo es el punto más conflictivo de los argumentos presentados por el filme sobre la ciudad soñada. ${ }^{9}$ ¿Cómo reproducir la novedad en el futuro? Los niños parecen incorporar el devenir temporal desde el momento en que representan naturalmente el futuro. Sin embargo, el límite de edad impuesto en la Ciudad Infantil se cierne como una barrera que encierra e inmoviliza, como si la inmovilidad y la falta de libertad fuera el precio a pagar por la rapidez con que han podido disfrutar de la utopía realizada. Esta ciudad donde todo es simultáneamente nuevo es posible porque suprime la historia que deja huellas en las ciudades construidas lentamente y porque hace presente lo que una acumulación a escala humana demoraría mucho tiempo en conseguir. El peronismo tuvo la capacidad para hacer presente lo que otras utopías trasladan a un futuro lejano o el cristianismo traslada, inclusive, a otra vida. El peronismo promete vivir el paraíso en la tierra: ya no es necesario morir para ver realizado el deseo. Pero lo hace en una ciudad improductiva donde se desconoce el origen de los recursos que se consumen y las claves para reproducirlos en el tiempo. La reproducción de la novedad — que tanto abrumó a las vanguardias - continúa aquí irresuelto. ¿Cómo hacer para sostener en el tiempo esta ciudad soñada?

La Ciudad Infantil fue en vida de Eva Duarte un destino obligado para visitantes extranjeros. Los relatos coinciden en señalar que era su obra más preciada. La tensión entre la ciudad postal y la ciudad vivida era presentada como una tensión resuelta entre prometer y cumplir. Perón y la primera dama abundan en citas donde se jactan de la capacidad del Gobierno para concretar proyectos: "No en vano tenemos como fuente de inspiración la doctrina y la obra del general Perón, que niega y rechaza el fácil halago de las promesas para exaltar el valor efectivo de las realizaciones". La celeridad con que se finalizaron las obras de la Ciudad Infantil es otra muestra de esa capacidad para convertir el futuro en presente. A modo de revancha, apenas derrocado el Gobierno de Perón, la destrucción de la Ciudad Infantil no se hizo esperar. La saña aplicada a su desaparición parece la prueba de su eficacia para encarnar sueños. Se dice que Diana Myriam Jones, la actriz infantil que encarnó a Blanquita, bautizada por las revistas de la época

9 Para una concepción de "lo nuevo", fue de utilidad el ensayo de Groys (2005). 
como "la Shirley argentina”, abandonó su carrera artística en 1956, apenas un año después del derrocamiento del Gobierno que la volvió protagonista de los sueños. Como el nombre de la protagonista (Blanquita), la blancura luminosa de los edificios de la Ciudad Infantil no permitía ver la orfandad de los niños que la habitaron. Como el castillo de Neuschwanstein imitado por Disney, la Ciudad Infantil también anunciaba alguna pesadilla.

\section{Referencias}

Amadori, L. C. (Director). (1938). Madreselva [película]. Argentina: Argentina Sono Film.

Amadori, L. C. (Director). (1951). Soñemos [película]. Argentina: Secretaría de Prensa y Difusión.

Anderson, B. (1993). Comunidades imaginadas: reflexiones sobre el origen y la difusión del nacionalismo. Buenos Aires, Argentina: Fondo de Cultura Económica.

Baczko, B. (2001). Lumières de l’utopie. París, Francia: Payot.

Ballent, A. (2005). Las huellas de la política: vivienda, ciudad y peronismo en Buenos Aires, 1943-1955. Buenos Aires, Argentina: Universidad Nacional de Quilmes, Prometeo.

Barth, M. (Director). (1951). La mujer puede y debe votar [película]. Argentina: Secretaría de Prensa y Difusión.

Borges, J. L. (1955). L' illusion comique. Sur, 237, 9.

Gené, M. (2005). Un mundo feliz: imágenes de los trabajadores en el primer peronismo 1946-1955. Buenos Aires, Argentina: Fondo de Cultura Económica.

Groys, B. (2005). Sobre lo nuevo. Valencia, España: Pre-textos. 
Kriger, C. (2009). Cine y peronismo: el Estado en escena. Buenos Aires, Argentina: Siglo XXI.

Mercado, S. (2013). El inventor del peronismo: Raúl Apold, el cerebro oculto que cambió la política argentina. Buenos Aires, Argentina: Planeta.

Moles, A. (1990). El kitsch: el arte de la felicidad. Barcelona, España: Paidós Ibérica.

Pappier, R. (Director). (1950). Payadas del tiempo nuevo [película]. Argentina: Secretaría de Prensa y Difusión.

Sirvén, P. (2012). Perón y los medios de comunicación: la conflictiva relación de los gobiernos justicialistas con la prensa 1943-2011. Buenos Aires, Argentina: Sudamericana.

Soria, A. (Director). (1952). Ahora soy un más [película]. Argentina: Secretaría de Prensa y Difusión.

Thompson, C. K. (2014). Picturing Argentina: Myths, movies and the peronist vision. Nueva York, EE. UU.: Cambria Press.

Tinayre, D. (Director). (1950). La vendedora de fantasías [película]. Argentina: Argentina Sono Film S.A.C.I.

Torre Nilsson, L. y Torres Ríos, L. (Directores). (1950). El crimen de Oribe [película]. Argentina: Estudios Mapol.

Varela, M. (2007). Le péronisme et les médias: contrôle politique, industrie nationale et goût populaire. Le Temps des médias, 2(7), 48-63. DOI: https://doi.org/10.3917/tdm.007.0048

Williams, R. (1992). Television: Technology and cultural form. Middletown, EE. UU.: Wesleyan University Press. 